\title{
The cell cycle effects of docosahexaenoic acid on human metastatic hepatocellular carcinoma proliferation
}

\author{
CAROL YEE-KI LEE ${ }^{1}$, WAI-HUNG SIT ${ }^{1}$, SHEUNG-TAT FAN ${ }^{2}$, KWAN MAN ${ }^{2}$, IRENE WING-YAN JOR ${ }^{1}$, \\ LEO LAP-YAN WONG ${ }^{1}$, MURPHY LAM-YIM WAN ${ }^{1}$, KIAN CHENG TAN-UN ${ }^{1}$ and JENNIFER MAN-FAN WAN ${ }^{1}$ \\ ${ }^{1}$ School of Biological Sciences, and ${ }^{2}$ Department of Surgery, The University of Hong Kong, \\ Pokfulam, Hong Kong, P.R. China
}

Received October 15, 2009; Accepted November 30, 2009

DOI: 10.3892/ijo_00000579

\begin{abstract}
Given the reported side effects associated with chemotherapy and surgical resection, dietary intervention with $\omega-3$ polyunsaturated fatty acids (PUFAs) has been postulated to be an alterative way to prevent liver cancer progression and metastasis. We studied the effects of an $\omega-3$ PUFA, docahexaenoic acid (DHA) on COX-2 expression and the cell cycle control machinery that co-ordinately regulate the HCC cells growth. Our data showed that DHA $(0-200 \mu \mathrm{M})$ retarded proliferation of the human metastatic HCC cell line MHCC97L dose-dependently. In addition, inhibition of cyclin $\mathrm{A} / \mathrm{Cdk} 2$ interfered with $\mathrm{S}$-phase progression further in agreement with the result of bivariate flow cytometric analysis which indicated that DNA synthesis time $\left(\mathrm{T}_{\mathrm{s}}\right)$ was significantly prolonged by DHA in MHCC97L. The N-myc oncogene, the heat shock proteins Hsp27 and glucose-related protein 78 (GRP78) as well as the antioxidant enzymes superoxide dismutase may play significant roles in the cell cycle control and reduced-proliferation of MHCC97L by DHA. Our data indicated that it is imperative to develop therapeutic strategy with $\omega-3$ PUFA that simultaneously targets COX-2 and other cell cycle regulators in hepatocarcinogenesis. This study provides novel mechanistic insights into the modulation of DHA on human hepatocarcinoma.
\end{abstract}

\section{Introduction}

During the last decade, there has been an upsurge of information on the role of polyunsaturated fatty acids in health and disease (1). As far as cancer growth is concerned, both human and animals studies have demonstrated that diet which

Correspondence to: Dr Jennifer Man-Fan Wan, School of Biological Sciences, Kadoorie Biological Science Building, The University of Hong Kong, Pokfulam Road, Hong Kong, SAR, P.R. China

E-mail: jmfwan@hkusua.hku.hk

Key words: hepatocellular carcinoma, cyclooxygenase-2, docosahexaenoic acid, $\omega-3$ fatty acids, cell cycle consists of high level of $\omega$-3 polyunsaturated fatty acids such as decosahexaenoic acid (DHA) and eicosapentaenoic acid (EPA) have anticancer properties against a variety of carcinomas (2-7). However, supporting evidence for the chemoprevention of DHA is only well documented for cancers of the breast, colon and prostate (2-7) but little is known about its effect against human liver cancers.

Hepatocellular carcinoma (HCC) is one of the most frequent visceral neoplasia in the world, with the incidence rates found higher in males compared to females (8). Widespread infection with hepatitis $\mathrm{B}(\mathrm{HBV})$ and hepatitis $\mathrm{C}$ (HCV) may account for the high prevalence of HCC in Asia and Africa (9). It is estimated that at least $75-80 \%$ of cases of primary $\mathrm{HCC}$ are attributable to chronic viral hepatitis, in addition to other risk factors including chronic alcohol misuse, non-alcoholic fatty liver disease (NAFLD), tobacco, oral contraceptives, and food contamination with aflatoxins $(9,10)$. Although surgical resection is the most effective treatment, HCC still has a poor prognosis since the incidence of intrahepatic recurrence is extremely high, even after curative operation. Severe side effects are the major drawback of chemotherapy and invasion and metastasis are the major obstacles to successful liver cancer treatment. Hence, improved therapies and preventive measures are urgently required. The investigation in dietary intervention is one of our proposed alternatives to prevent or assist treatment of liver cancer.

Few studies have indicated that $\omega-3$ PUFAs are capable of reducing growth of human hepatocarcinoma $(7,11)$, however, the cellular and molecular mechanism by which docosahexaenoic acid can inhibit cell cycle progression and induction of apoptosis of liver cancer remains to be understood. Once $\omega-3$ fatty acids are incorporated into membrane, they become a crucial component of the hydrophobic structure which affects fluidity, thickness, domain size, stability and permeability of the membrane and through interaction with membrane proteins such as transporters or protein kinases, they may alter signal transduction involved in various biochemical activities $(12,13)$. Because of their involvement in signal transduction, some studies have suggested that DHA may affect cell growth by altering cell-cycle progression, possible via the post-receptor signaling pathways (14). Specifically, fatty acid metabolism to prostaglandin E1 and E2 activates protein kinases $\mathrm{A}$ (through $\mathrm{cAMP}$ ) and $\mathrm{C}$ leading to 
the phosphorlyation of proteins targeted by tyrosine kinase and finally activates the progression of cells through the cell cycle (14). Previously, we demonstrated that dietary fish oil enriched with $\omega-3$ fatty acids prolonged the S-phase leading to extension of the potential doubling time of the mammary tumor in F334 rats (15). Subsequently, other investigators demonstrated that DHA arrests malignant cells in $\mathrm{S}$ phase (16) and prevents G1/S progression in human HT-29 colonic cells (17). Together, these observations indicated that DHA could exert its anti-cancer effects by arresting cell-cycle progression. $\omega$-3 fatty acid-mediated cell cycle-arrest probably due to control of the cell cycle regulatory cyclins and their partner kinases (Cdks) $(17,18)$. Accordingly, this study was designed to investigate whether DHA may affect growth by altering cell-cycle progression in the human hepatocarcinoma cancer MHCC97L cell line of low metastatic potential and whether cyclin E, a mediators of G1 late phase, and cyclin A, and S-phase progression (19) and their partner kinase CDK2 were involved. Our results indicated that DHA-mediated Sphase toxicity in the MHCC97L cells and the process involved the suppression of the cell cycle regulatory proteins cyclin $\mathrm{E}$ and cyclin A and their partner kinase Cdk2.

Existing evidence indicates that the multiple pathway cross-talk with DHA affects cell growth and viability. The $\omega-3$ fatty acids can modulate cancer growth through the alteration of membrane phospholipid turnover, release of membrane arachidonic acid (AA) from phospholipids, and prostaglandin (PG) synthesis via cyclooxygenase-2 (COX-2) enzymes (20), as well as lipid peroxidation (14). In order to obtain better insight into the anticancer mechanisms of DHA-mediated toxicity to MHCC97L cells, we also measured the protein expression of $\mathrm{COX}-2$, the heat shock proteins Hsp27 and GRP78, the oncogene N-myc, and antioxidant enzymes SOD2 in a separate study. Our results indicated the DHA-mediated toxicity to human liver cancer was in part, via the activation/deactivation of the COX-2, the heat shock, $\mathrm{N}$-myc, and oxidative stress-related pathways. The present study provides some novel cellular and molecular insights in the modulation of DHA on human liver cancer and the data have further strengthen our hypothesis that DHA is a potential chemopreventive agent for human liver cancers.

\section{Materials and methods}

Reagents. Human hepatocarcinoma cell line, MHCC97L, was originally obtained from the Liver Cancer Institute (Fudan University, Shanghai, China). Dulbecco's modified Eagle's medium (DMEM), fetal bovine serum, sodium pyruvate, penicillin-streptomycin and Fungizone ${ }^{\circledR}$ were obtained from Gibco (Grand Island, NY). Anti-BrdUrd monoclonal antibody, anti- $\beta$-actin monoclonal antibody, goat anti-mouse IgG (FITC labeled) antibody, goat anti-mouse IgG (peroxidase labeled), propidium iodide (PI), 5'-Bromo-2'-deoxyuridine (BrdUrd), cis-4,7,13,16,19-docosahexaeonic acid sodium salt (DHA); 3-(4,5-dimethylthiazol-2-y)-2,5-diphenyltetrazolium bromide (MTT) protease inhibitor cocktail set I and isopropanol were obtained from Sigma (St. Louis, MO). Anti-COX-2, anti-N-myc, anti-PKC $\alpha$, anti-glutathione synthetase, anti-SOD 2, anti-GRP78 and anti-Hsp27 were purchased from Abcam (Cambridge, UK). Enchanced chemilu- minescence substrate (ECL) and polyvinylidene difluoride (PVDF) membrane were obtained from GE Healthcare BioSciences.

Cell line, cell culture and DHA treatment. The human hepatocarcinoma cancer cell line (MHCC97L) with $40 \%$ spontaneous pulmonary metastasis occurred in recipient nude mice after orthotopic inoculation (21) was established from the parent cell line MHCC97. The cells, shown to be of human origin by karyotype analysis, grow either as clusters or as a monolayer with approximately $31 \mathrm{~h}$ doubling time (22). The MHCC97L cells exhibited $40 \%$ pulmonary metastatic rate and is considered a low metastatic cell line as compared to the MHCC97H cell line, which exhibited $80 \%$ pulmonary metastatic rate, when injected into nude mice (22). For the cell culture and DHA treatment, the MHCC97L cells were routinely cultured in high glucose Dulbecco's modified Eagle's medium (DMEM) medium supplemented with heat inactivated FBS $(10 \% \mathrm{v} / \mathrm{v})$, sodium pyruvate $(1 \mathrm{mM})$ and antibiotics $(50 \mathrm{U} / \mathrm{ml}$ penicillin, $50 \mu \mathrm{g} / \mathrm{ml}$ streptomycin and $2.5 \mu \mathrm{g} / \mathrm{ml}$ Fungizone) in a humidified atmosphere at $37^{\circ} \mathrm{C}$ with $5 \% \mathrm{CO}_{2}$. The cells were monitored carefully to ensure they did not exceed $80 \%$ confluent. A DHA stock solution (8 $\mathrm{mM}$ ) was prepared by dissolving sodium salt of the DHA in PBS. Cells were treated with various concen-trations of DHA (0-200 $\mu \mathrm{M})$ for up to $72 \mathrm{~h}$.

Cell proliferation assay. The dose-dependent effect of DHA on cell viability was assessed by using the MTT staining method as previously described (23). Briefly, the suspended cells $\left(1 \times 10^{4}\right.$ cells/well) were dispersed into the wells of 96 -well microtiter plates. After $24 \mathrm{~h}$ incubation, various concentrations of DHA were added to the cells in each well. At the end of the $72 \mathrm{~h}$ DHA incubation, the medium was removed and $50 \mu \mathrm{l}$ of MTT solution ( $1 \mathrm{mg} / \mathrm{ml}$ in C-DMEM) was added. The cells were incubated with the MTT solution for $2 \mathrm{~h}$ at $37^{\circ} \mathrm{C}$. At the end of the incubation, MTT solution was removed and the insoluble purple formazan crystals were dissolved in $50 \mu \mathrm{l}$ of isopropanol with $0.1 \mathrm{M} \mathrm{HCl}$. The optical density (OD) of each well was read on a Bio-Rad 550 Microplate Reader at $595 \mathrm{~nm}$ with a reference wavelength at $655 \mathrm{~nm}$. The percentage of cell viability was expressed as $\left(\mathrm{A}_{\text {treatment }}\right.$ ) $\left.\mathrm{A}_{\text {control }}\right) \times 100 \%$.

Bivariate BrdUrd/DNA flow cytometric analysis of cell cycle kinetics. The cell cycle kinetics analysis was achieved by using the bivariate BrdUrd/DNA flow cytometry technique as previously described by our group (24) and other investigators (25-27). The method is based on simultaneous measurement of the total incorporation or the rate of incorporation of the thymidine analog, BrdUrd, into newly synthesized DNA. The uptake of BrdUrd in each cell can be detected by immunocytochemical staining techniques that involve binding in the BrdUrd to fluorescein isothiocyanate-labeled anti-BrdUrd monoclonal antibodies (green fluorescence). The quantity of BrdUrd (green fluorescence) and DNA (red fluorescence labels by PI) can be simultaneously measured in the same cells. This analysis estimates the relative number of cells actually involved in cell division (labeling index) and may also provide estimates of the rate of DNA synthesis. 


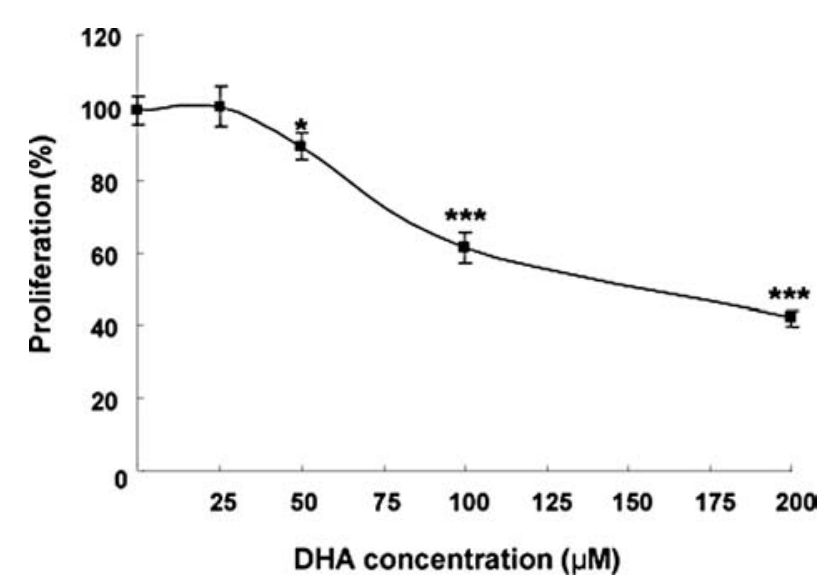

Figure 1. The effect of DHA on the proliferation of human liver cancer MHCC97L. Cells were exposed to different concentrations of DHA for $72 \mathrm{~h}$. The viability of cells was determined by MTT assay. Data are expressed as mean $\pm \operatorname{SEM}(\mathrm{n}=6){ }^{*}{ }^{* * * *} \mathrm{P}<0.05$ and 0.001 respectively, vs. control.

To study the cell cycle kinetics [labeling index (LI), relative movement (RM), DNA synthesis time $\left(T_{s}\right)$ and $G_{0} / G_{1}$ cells returned or labeled divided cells (Ld)], approximately $2.5 \times 10^{6}$ exponentially growing MHCC $97 \mathrm{~L}$ cells were incubated with DHA $(50 \mu \mathrm{M})$ for $72 \mathrm{~h}$. After treatment, both DHAtreated and untreated cells were pulsed-labeled with $10 \mu \mathrm{M}$ of BrdUrd for $30 \mathrm{~min}$ at $37^{\circ} \mathrm{C}$. Excess BrdUrd was then removed by washing twice with the medium before further incubation for 1 and $9 \mathrm{~h}$, respectively. To obtain a good average, three flasks were prepared for each time point. At the end of incubation, the cells were fixed with $70 \%$ ice-cold ethanol and stored at $-20^{\circ} \mathrm{C}$ until further analysis by flow cytometry.

Immunocytochemical staining for BrdUrd/DNA flow cytometry analysis. Staining of cells for bivariate analysis of BrdUrd/ DNA flow cytometry analysis was performed as previously described by our group (24). Prior to staining of $2 \times 10^{6} \mathrm{BrdUrd}$ incorporated cells, fixative was removed by washing twice with PBS and the DNA of cells were partially denatured by incubation with $2 \mathrm{M} \mathrm{HCl}$ for $20 \mathrm{~min}$ at room temperature. After partial denaturation, the cells were washed 3 times with PBS containing $0.05 \%$ Tween-20 (PBS-T). The cells were incubated with $100 \mu 1$ anti-BrdU monoclonal antibody (1:100) for $1 \mathrm{~h}$ and subsequently washed 3 times with PBS-T. The cells were further incubated with $100 \mu \mathrm{l}$ of FITC-conjugated anti-mouse IgG antibody (1:40) to label the primary antibodies for $1 \mathrm{~h}$ at room temperature in the dark. The cells were then washed twice with PBS before resuspended in $1 \mathrm{ml}$ of Vindelov's propidium iodide (VPI) solution $(50 \mathrm{mg} / \mathrm{l} \mathrm{PI}, 0.01 \mathrm{M}$ Tris, $10 \mathrm{mM} \mathrm{NaCl}, 10 \mathrm{mg} / \mathrm{l}$ RNAase and $1 \mathrm{ml} / \mathrm{l}$ Nonidet P-40, $\mathrm{pH}$ 8.0). Samples were ready for analysis by flow cytometry after $15 \mathrm{~min}$.

The cells were analyzed with a Coulter EPICS flow cytometer (Miami, FL, USA), with the excitation light at 488 $\mathrm{nm}$. Red fluorescence from PI was collected through a 620 $\mathrm{nm}$ band-pass filter as the total DNA content. Green fluorescence from the FITC-labeled anti-BrdUrd antibody was collected through a $525 \mathrm{~nm}$ band pass filter. Cell debris
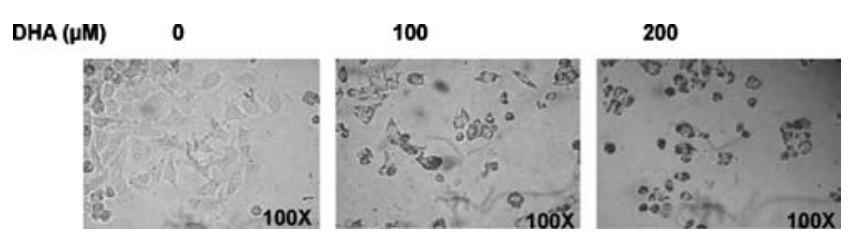

Figure 2. DHA affects cellular morphology and adhesion of MHCC97L. Cells were treated without (control) or DHA (100 and $200 \mu \mathrm{M})$ for $72 \mathrm{~h}$. Microscopic examination at magnification x100 shows cells with normal, adherence, uniformly extended morphology in the control (0 ml DHA). The DHA-induced dose-dependent morphological change in the MHCC97L cells includes of increased cell flattening, reduced adhesion but increased detachment of the cells to the plate (folding).
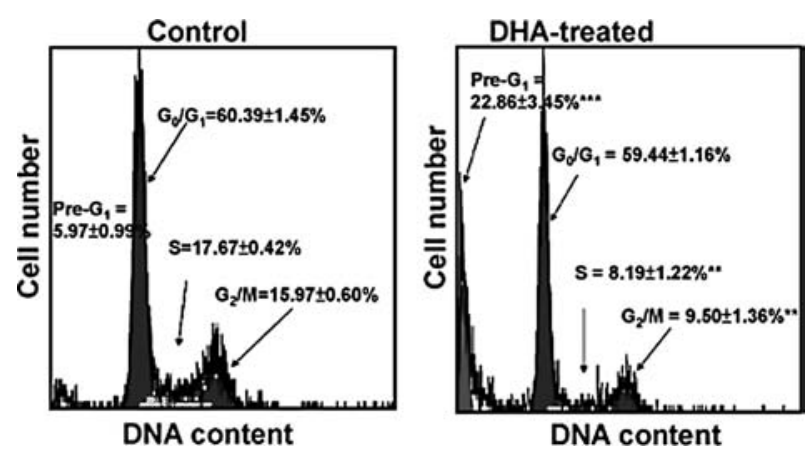

Figure 3. Effect of DHA on the cell cycle distribution of MHCC97L cells. Cells without (control) or with DHA $(50 \mu \mathrm{M})$ incubation for $72 \mathrm{~h}$ were fixed with PI for staining of DNA. The cell population (\%) distribution among the pre- $G_{1}, G_{0} / G_{1}, S$ and $G_{2} / M$ phase was analyzed by DNA/PI flow cytometry. Data are expressed as mean $\pm \operatorname{SEM}(n=6) .{ }^{* *} \mathrm{P}<0.01,{ }^{* * *} \mathrm{P}<0.001$ compared with control.

was excluded from analysis by elevating the threshold of the red fluorescence. The same equipment settings were used for all determination and the parameters 10,000 cells were collected for each sample.

Cytokinetic calculations. The bivariate BrdUrd/DNA analysis allows separation of cells according to the cell-cycle phase $(24,25)$. By repeating the bivariate BrdUrd/DNA analysis of labeled cells at different time points, it is possible to determine the rate of progression of BrdUrd-labeled cells as they accumulate more DNA. The movement of the BrdUrdlabeled cells (cycling cells) between the $\mathrm{G}_{0} / \mathrm{G}_{1}$ and $\mathrm{G}_{2} / \mathrm{M}$ cell cycle phases can be used to calculate the 'relative movement' (RM). By using two different relative movements [RM(t)] extracted from the different BrdUrd pulse-labeling time, the DNA synthesis time $\left(T_{s}\right)$ of the cancer cells can be calculated according to the methods previously described (24-26):

$$
\begin{aligned}
& \mathrm{RM}(\mathrm{t})=\left(\mathrm{F}_{\mathrm{lud}(\mathrm{t})}-\mathrm{F}_{\mathrm{G} 0 / \mathrm{G} 1}\right) /\left(\mathrm{F}_{\mathrm{G} 2 / \mathrm{M}}-\mathrm{F}_{\mathrm{G} 0 / \mathrm{G} 1}\right) \\
& \mathrm{Ts}=0.55(\mathrm{t}) /[\mathrm{RM}(\mathrm{t})-\mathrm{RM}(0)]
\end{aligned}
$$

Where $\mathrm{F}_{\mathrm{lud}(\mathrm{t})}, \mathrm{F}_{\mathrm{G} / \mathrm{G} 1}$ and $\mathrm{F}_{\mathrm{G} 2 / \mathrm{M}}$ are the mean PI fluorescence (DNA content) of the BrdUrd labelled undivided cells of the $\mathrm{G}_{0} / \mathrm{G}_{1}$ and $\mathrm{G}_{2} / \mathrm{M}$ population at time (t) (hour) after BrdUrd pulsing. $\mathrm{RM}(0)$ and $\mathrm{RM}(\mathrm{t})$ are the relative movement values at time 0 and $t$ (hour) after BrdUrd pulsing respectively. $\mathrm{RM}(0)$ is estimated to be 0.55 . 
(a) $1 \mathrm{~h}$

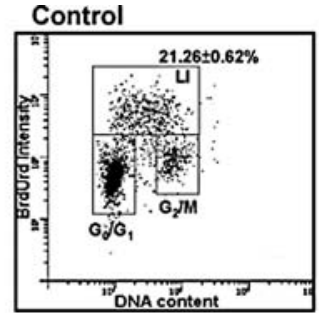

(b) $9 \mathrm{~h}$

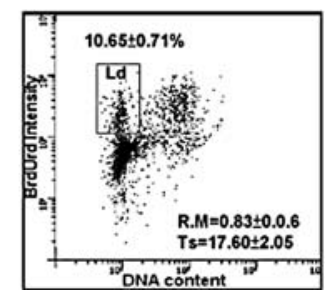

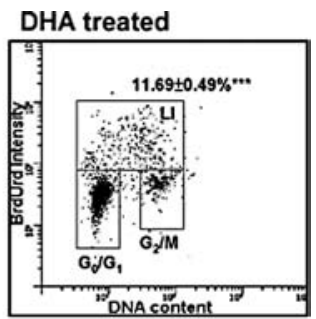

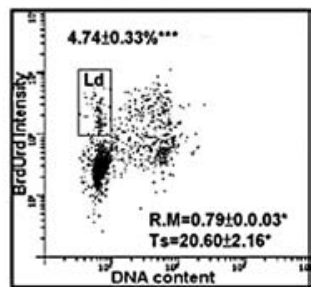

Figure 4. Effect of DHA on cell cycle kinetic parameters measured by bivariate BrdUrd/DNA flow cytometry. The dot plots presentation of the bivariate BrdUrd/DNA flow cytometry analysis is for cells without DHA (control) and with DHA $(50 \mu \mathrm{M})$ treatment for $72 \mathrm{~h}$ and after pulse-labeled with BrdUrd for $1 \mathrm{~h}$ (a) and $9 \mathrm{~h}$ (b), respectively. The y-axis represents the FITC-BrdU signal while the $\mathrm{x}$-axis represents the signal of PI stained DNA. Cells at $\mathrm{G}_{0} / \mathrm{G}_{1}$ and $\mathrm{G}_{2} / \mathrm{M}$ phase were not labeled with BrdUrd and situated separately at DNA content of $2 \mathrm{~N}$ and $4 \mathrm{~N}$, respectively. S phase cells situated between $2 \mathrm{~N}$ and $4 \mathrm{~N}$ were labeled with BrdU. The labeling index (LI) was calculated as the total percentage of BrdUrd-positively-labeled cells in the S-phase of the $1 \mathrm{~h} \mathrm{BrdUrd} \mathrm{label} \mathrm{(Fig.} \mathrm{4a).} \mathrm{After} 9 \mathrm{~h}$ incubation, some $\mathrm{S}$ phase cells incorporated with BrdUrd progressed through $\mathrm{G}_{2} / \mathrm{M}$ phase and underwent cell division, these cells are regarded as labeleddivided cells $(\mathrm{Ld})$. Values are mean $\pm \operatorname{SEM}(\mathrm{n}=3)$. ${ }^{*} \mathrm{P}<0.05,{ }^{* * *} \mathrm{P}<0.001$ compared with control.

Western blot analysis. Total protein $(20 \mu \mathrm{g} / \mathrm{lane})$ extracted from $1 \times 10^{7}$ cells was separated by $12.5 \%$ SDS polyacrylamide gels and transferred onto PVDF membrane with TE77 PWR semi-dry transfer unit. The membranes were blocked with 5\% non-fat dry milk in PBS overnight at $4^{\circ} \mathrm{C}$ and then washed with PBS-T. The membranes were incubated at room temperature for $1 \mathrm{~h}$ with each of the examined proteins primary antibodies following with incubation with horseradish peroxidase conjugated secondary antibodies (1:2000). Antibody labeling of protein bands was detected with ECL solution for $5 \mathrm{~min}$ before exposed to film.

Statistical analysis. Data were summaried as mean \pm SEM and analysed by one way analysis of variance (ANOVA) after Bonferroni's Multiple Comparison test. Results were compared by Student's paired t-test. A significance level of 0.05 was used for all comparisons.

\section{Results}

Treatment with DHA reduces interference with adhesion and proliferation of the MHCC97L cells. Fig. 1 shows that DHA reduced proliferation of MHCC97L in a dose-response manner. Under microscopic observeration (Fig. 2), the MHCC97L cells appeared to have lost their adhensive property increasingly with 100 and $200 \mu \mathrm{M}$ of DHA treatment as compared to control (0 $\mu \mathrm{M}$ DHA). The MHCC $97 \mathrm{~L}$ adhesion follows a defined pattern, which is altered by DHA in a dosedependent manner (Fig. 2). Control cells were flattened,

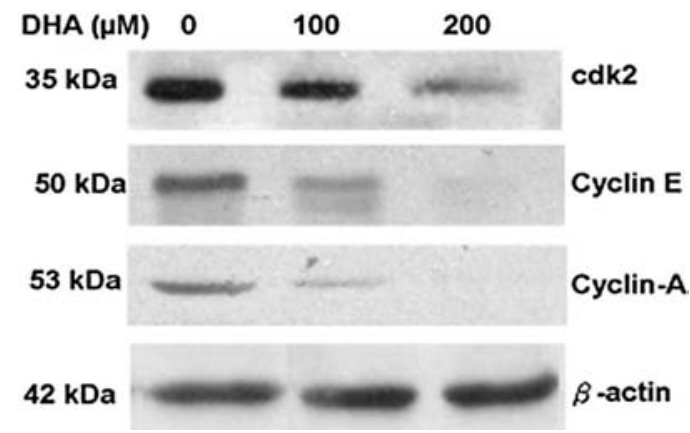

Figure 5. Effect of DHA on protein levels of the cell cycle regulatory proteins: cyclin A, cyclin E and Cdk2. MHCC97L cells are treated with 0 (control), 100 and $200 \mu \mathrm{M}$ of DHA for $72 \mathrm{~h}$. Cell lysates were examined by Western blot analysis with antibodies against Cdk2, cyclin E and cyclin A.

attached, extended and resistant to aspiration. The reduction in adherence caused by DHA is concomitant with alternations in the morphologic changes. The cells treated with DHA were not only unable to extend processes, but were fully nonadherent and freely floating in the cell culture (Fig. 1).

DHA reduces $M H C C 97 L$ labelling index (LI) and their distribution in $S$ - and $G 2 / M$ phase. It is well documented that a number of drugs exert their anticancer effects via the inhibition of cell cycle progression. Existing evidence also demonstrated that $\omega-3$ PUFAs exhibits cell cycle-dependent effect on various cancers (15-17). We therefore hypothesized that DHA reduced MHCC97L cell proliferation may involve similar mechanisms. A low dose $(50 \mu \mathrm{M})$ DHA was chosen for the cell cycle kinetics study as we encountered difficulty in flow measurement of less cells due to large number of cells lost with higher doses of DHA. Fig. 3 shows the influence of DHA on the DNA distribution of the cancer cells among the $\mathrm{G}_{0} / \mathrm{G}_{1}, \mathrm{~S}$ and $\mathrm{G}_{2} / \mathrm{M}$ phases. In the control, the distribution of cell populations in $\mathrm{G}_{0} / \mathrm{G}_{1}, \mathrm{~S}$ and $\mathrm{G}_{2} / \mathrm{M}$ was $60.39 \pm 1.45 \%$, $17.67 \pm 0.42 \%$ and $15.97 \pm 0.60 \%$, respectively, with fewer $(5.97 \pm 0.99 \%)$ cell populations in the Pre $-G_{1}$ peak (measurement of DNA fragments by apoptosis) (Fig. 3). DHA induced significant $(n=6 ; p<0.01)$ reduction of cells in the S-phase and $G_{2} / M$ phase without affecting the $G_{0} / G_{1}$ cell populations. With $72 \mathrm{~h}$ treatment, the Pre- $\mathrm{G}_{1}$ peak cell population was increased by 2.8 -fold, indicating that DHA induces cell death of the liver cancer cell line.

DHA delays both DNA synthesis (Ts) and cell division. The total amount of BrdUrd-postive-labeled cells is a measure of the labeling index (LI), which reflects the total number of cells engaged in DHA synthesis during the time of study; and the progression of BrdUrd-labeled cells to the $\mathrm{G}_{2} / \mathrm{M}$ phase is a measure of the DNA synthesis time $\left(\mathrm{T}_{\mathrm{s}}\right)$, which can be calculated via determination of the relative movement (RM) of the cells. The bivariate BrdUrd/DNA flow cytometric analyses of the 1 and $9 \mathrm{~h} \mathrm{BrdUrd} \mathrm{labeling} \mathrm{are} \mathrm{presented} \mathrm{in} \mathrm{Fig.}$ $4 \mathrm{a}$ and $\mathrm{b}$, respectively, as dot plots. DHA significantly $(p<0.001)$ reduced LI, movement of the cells through $S$ phase and cells division, resulting in less number of cells capable of returning to $G_{1}(L d)$. The progression of the 
(a)
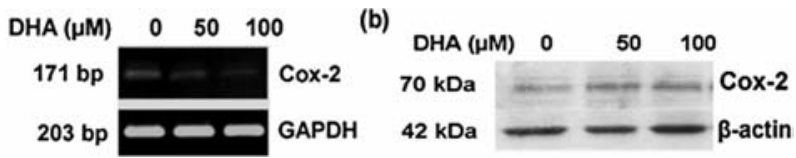

Figure 6. Effect of DHA on both transcriptional and translational expression of cyclooxygenase-2 (COX-2) in MHCC97L cells. Cells were incubated with 0 (control), 50 and $100 \mu \mathrm{M}$ of DHA for $72 \mathrm{~h}$. (a) The gene expression of COX-2 was quantified by real-time PCR and calculated with the second derivative $\left(2^{-\Delta \Delta C t}\right)$ method. Data are expressed as mean $\pm \operatorname{SEM}(n=6)$. ${ }^{* * *} \mathrm{P}<0.001$ compared with control group by using Bonferroni's multiple comparison test. (b) Protein level of COX-2 detected by Western blot analysis with no significant change of expression level with DHA treatment.

BrdUrd-labeled cells to the $\mathrm{G}_{2} / \mathrm{M}$ phase provides the estimation of the relative movement of the cells, which can be used to calculate the DNA synthesis time $\left(\mathrm{T}_{\mathrm{s}}\right)$ according the White et al and Begg et al $(26,27)$ and previously adopted by our group $(24,28)$. The RM was deduced from the $9 \mathrm{~h}$ BrdUrd label, which was significantly slower with DHA, was used to predict the DNA synthesis $\left(\mathrm{T}_{\mathrm{s}}\right)$. $\mathrm{T}_{\mathrm{s}}$ was found to be extended from $17.60 \pm 2.05$ to $20.60 \pm 2.16 \mathrm{~h}$ after DHA treatment (Fig. 4b). DHA treatment significantly $(\mathrm{p}<0.05)$ delayed $\mathrm{T}_{\mathrm{s}}$ of MHCC $97 \mathrm{~L}$ by approximately $3 \mathrm{~h}$. With a significant reduction of the $\mathrm{Ld}(\mathrm{p}<0.001)$ from $10.65 \pm 0.71 \%$ (control) to $4.74 \pm 0.33 \%$ (DHA), the BrdUrd/DNA of the $9 \mathrm{~h}$ BrdUrd label clearly suggests that DHA is also capable of inhibiting cell division (Fig. 4b). Together, the cytokinetic data indicate that DHA possesses cytostatic action to the liver cancer cells and that the delay in S-phase duration may account for the overall growth reduction of the MHCC97L cell line.

The cell cycle effect of DHA on MHCC97L cells involves cyclin $E$ and cyclin $A$ and $C d k 2$. Cell cycle time varies in different cell types as a consequence of differences in the time spent between cytokinesis and the restriction point (i.e. $\left.\mathrm{G}_{1}\right)$. Progression through each phase $\left(\mathrm{G}_{1}, \mathrm{~S}, \mathrm{G}_{1} / \mathrm{M}\right)$ of the cell cycle is under the strict control of the cyclins and their partner kinases (Cdks) (19). In a separate experiment, we measured the influence of DHA (100 and $200 \mu \mathrm{M})$ on the cell cycle check points cyclin A and cyclin E by Western blot analysis. Fig. 5 shows that cyclin A, which takes part in the rate limiting step for DNA replication and cyclin E, which controls cell entry from late $G_{1}$ to $S$ phase (29), were significantly reduced with DHA treatment. In general, the levels of Cdks are said to be relatively constant throughout the cell cycle, whereas the cyclins level vary substantially (19) and Cdk2 was also reduced in cells with DHA treatment. These results indicate that the cell cycle controls of DHA of the human liver cancer cells involve cyclin A and cyclin E and their partner Cdk2 kinase.

DHA reduces COX-2 expression at the $m R N A$ level but not at protein level of MHCC $97 \mathrm{~L}$ cells. Overexpression of COX-2 is said to be associated with increased HCC malignancy (30) and $\omega-3$ PUFA treatment has been found to inhibit its expression (31). It has been proposed that n-3 PUFAs are able to incorporate into tumor phospholipids at the expense of n-6 PUFAs (32) and compete with AA as substrate in the

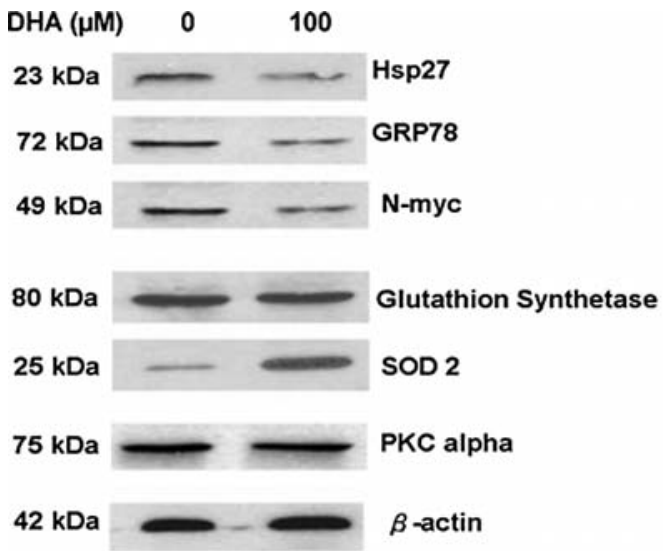

Figure 7. Effect of DHA on protein levels of Hsp27, GRP78, N-myc, glutathione synthetase, SOD2 and protein kinase C in MHCC97L cells. Cells were treated with 0 (control) and $100 \mu \mathrm{M}$ of DHA for $72 \mathrm{~h}$. Cell lysates were examined by Western blot analysis with antibodies against Hsp27, GRP78 and N-myc (chaperone/stress response related proteins), glutathione synthetase and SOD2 (antioxidation and detoxification related proteins) and $\mathrm{PKC} \alpha$.

COX-2 pathway. COX-2 inhibitor has been shown to induce cell cycle arrest and reduced cancer proliferation in $\mathrm{HCC}$ cells (33). With the assumption that DHA-mediated cytotoxicity to MHCC $97 \mathrm{~L}$ cells was COX-2 dependent, we measured COX-2 expression at the mRNA level by RT-PCR (Fig. 6a) and protein level (Fig. 6b) by Western blot. It was found that MHCC97L cells expressed COX-2 as endogenous gene and DHA treatment reduced $(\mathrm{p}<0.01)$ its transcriptional level dose-dependently, however, the protein level of COX-2 was not as apparently changed or even slightly increased (Fig. 6b). The low COX-2 protein/mRNA was unexpected, but has been reported in colon cancer (34), and is related to some interference of microRNAs (34).

DHA reduces protein levels of Hsp27, GRP78, N-myc, increases SOD2 with no effect on glutathione synthase and protein kinase $C$. It was interesting to see that multiple pathways are involved in DHA-mediated cytotoxicity to the human liver cancer cells. Fig. 7 shows that the heat shock protein Hsp27, ER-related protein GRP78, and oncogene $\mathrm{N}$-myc were all reduced in DHA-treated cells. DHA however increased the level of the antioxidant enzyme SOD2, but had no effect on glutathione synthetase and protein kinase C. These data confirmed that DHA-reduced MHCC97L cell proliferation involves multi-pathways and the cytotoxic effect of DHA to human hepatocarcinoma.

\section{Discussion}

$\omega-3$ fatty acids inhibit the growth of human liver cancer cells both in vivo and in vitro $(7,11)$. At present, however, little is known about the underlying mechanisms of DHA on cell proliferation and apoptosis of human hepatocarcinoma. By using the human hepatocarcinoma cell line MHCC97L, we show that DHA can mediate cell cycle arrest (cytostatic, inhibits DNA synthesis) and cytotoxic (induction of apoptosis) effects. The cell cycle kinetics data show that the significantly longer S-phase duration in $\omega$-3 PUFA feeding 
may account for the overall slower proliferation of the cancer cells. The present study also shows that DHA treatment reduced heat shock protein Hsp27 and the ER related protein GRP78 as well as the oncogene $\mathrm{N}$-myc; increased expression of SOD but with no effect on glutathione synthetase and protein kinase (Fig. 7). The significant changes of these proteins suggest that DHA-reduced MHCC97L cell proliferation involves of multi-pathways and that the cytotoxic effect of DHA to the human hepatocarcinoma may also be via a free radical dependent process, heat shock pathway, in addition to that of the COX-2 prostanoid pathways. To our knowledge, this is the first detailed study on the effect of DHA on a low metatastic human hepatocellular carcinoma. Our data corroborate prior reports on diet enriched with $\omega-3$ fatty acids preventing primary liver tumor growth in vivo $(6,7)$ and in vitro (11).

Our own interest in exploring the regulation of cell cycle control of DHA emanated from our previous study of the breast carcinoma animal model in which it showed that the significantly longer S-phase duration in $\omega$-3 PUFA feeding accounted for the overall slower growth of the tumor (35). The present study shows that DHA significantly reduced the rate of BrdUrd movement relative to DNA content, indicating prolongation of the S-phase duration $\left(\mathrm{T}_{\mathrm{s}}\right)$ or DNA replication time. We observed that there were fewer cells in the $S$ phase of the cell cycle in DHA-treated cells than in the control cells (Fig. 4a). Similarly, the number of cells in the $\mathrm{G}_{2} / \mathrm{M}$ phase of the cell cycle was lower in DHA-treated cells than in the control cells. These findings, which accounted at least, in part for the decreased cancer cell proliferation, represent the first description of an alternation in $S$ phase duration in the metastasis of human hepatocarcinoma cells by DHA.

The fact that cyclin E and cyclin A protein levels were reduced after DHA treatment supported that DHA-mediated S-phase transit delay was a cell-cycle regulatory event (Fig. 5). In growth-stimulated cells, the activity of cyclin E/Cdk2 complex reaches its maximum in late-G1-S-phase transition (29). DHA was shown to inhibit cyclin E phosphorylation and Cdk2 levels in FM3A mouse mammary cancer cells. Progression through each phase of the cell cycle is tightly regulated and involves the expression and rapid degradation of the cyclin A-Cdk2 complex (19). Cyclin A appears in S phase with the onset of DNA synthesis. We suspected that cyclin A might then take part in a rate-limiting step for DNA replication since it can accelerate entry into S-phase when overexpressed. Our observations on the cell cycle specific effects of DHA on the inhibition of the $G_{1} / S$ progression in liver cancer cells agreed with findings of other investigators that DHA arrests malignant cells in $\mathrm{S}$ phase (16), FM3A mammary cancer cells in $G_{0} / G_{1}$ and prevents $G_{1} / S$ progression in human HT-29 colonic cells (17), vascular smooth muscle cells (18) and human Jurkat leukemia cells (36).

$\omega-3$ fatty acid suppression of COX-2 has been associated with reduced tumorigenicity. Evidence suggests that $\omega-3$ fatty acids may affect cancer cell growth by altering the production of eicosanoid hormones from arachidonic acid (AA) via COX-2 enzymes (20). Overexpression of COX-2 are related to poorer prognosis in liver cancer patients (30) indicating that the metabolites of AA such as PGE2 play an important role in tumorigenesis $(30,38)$. Suppression of PGE2 production by COX-2 inhibitors in hepatoma cell lines has been associated with decreased BrdUrd uptake (38). Since eicosanoids were not determined in the present study, it is however unknown whether DHA-mediated cell cycle arrest and increase apoptosis in the MHCC97L cell line were COX2-prostanoids-dependant (Fig. 3). Reduced COX-2 expression can inhibit both tumor cell proliferation and induce apoptosis in various cancers. The use of COX-2 inhibitor has been shown to induce cell cycle arrest and reduced cancer proliferation in HCC cells. Growth inhibition of human liver cancer cells by the COX-2 inhibitor JTE-522 was said to be in part mediated by the cell cycle arrest and the upregulation of peroxisome proliferator-activated receptor (PPAR)- $\gamma$ protein in HepG2 and PLC/PRF/5 cells (39). We have observed a significant decreased in COX-2 gene expression in the DHA-treated cells in this study (Fig. 5), indicating that the toxicity of DHA to the liver cancer cells may be COX-2dependent.

A possible connection between the suppressed COX-2 and the reduced $\mathrm{N}$-myc with cell cycle arrest of DHA is suspected here. In the neuroblastoma cell line GOTO, it has been shown that $\delta$ 12-prostaglandin (PG) J2 and PGA2 (derived from the COX-2 pathway) inhibited $\mathrm{G}_{1}$ cell cycle progression was closely associated with the suppression of the oncogene $\mathrm{N}$-myc through binding to nuclear proteins (40). It has been indicated that the transient expression of $\mathrm{N}$-myc during the prereplicative stage of liver regeneration may be associated with the entry of hepatocytes into the cell cycle. Furthermore, the N-myc downstream regulated gene 1 (NDRG1)/Cap43 expression has been found in advanced HCC and was thought to accelerate tumor invasion and metastasis $(41,42)$. The expression of NDRG1 has been proposed as a tumor maker for hepatocellular carcinoma in human as its overexpression has been correlated with tumor differentiation, vascular invasion and overall survival (42). To obtain a clear view on the cell cycle and cell death signaling control of COX-2-prostanoids of DHA, future studies should involve measurement not only the $\mathrm{E}$, but also the $\mathrm{J}$ and $\mathrm{A}$ series of prostaglandins.

The reduction of Hsp27 and GRP78 proteins suggest that the chaperon/heat shock pathway may play some important roles in DHA-induced toxicity to the human liver cancer cells. Generally speaking, the changes in heat shock protein response would contribute to various cancer related processes including cell proliferation, differentiation, inflammatory response, programmed cell death, DNA repair, angiogenesis, and metastasis (43). Hsp27 plays an essential role in the regulation of cell adhesion, proliferation, migration and invasion by interacting with protein kinase $\mathrm{C}$ and mitogenactivated protein kinase (MAPK) superfamily $(43,44)$. Several studies pointed out that Hsp27 is highly inducible in a number of cancers such as breast, renal leukemia and HCC $(44,45)$. The precise roles of Hsp27 in the human liver cancer are unclear, but enhanced level of this protein has been found to be associated with resistance to heat shock and many chemotherapeutic agents (46). The glucose-related protein 78 (GRP78) belongs to the heat shock protein 70 families, and is an important calcium-binding chaperone expressed and localized ubiquitously in the endoplasmic reticulum (ER) (43). It is a stress inducible ER chaperone with anti-apoptotic 
properties (47). An elevated GRP78 level appears to protect the cancer cells against adverse physiology and environmental conditions, such as glucose and oxygen deprivation and cytotoxic effect of chemotherapeutic drugs (48). We suspect that the reduction of GRP78 protein plays a role in the cell death process of DHA since ER stress-induced mitochondriamediated apoptosis has been related to heat shock protein inhibition. The initiation of endoplasmic recticulum (ER) stress has been suggested to play potential roles in hepatocarcinogenesis and that cell-cycle regulators such as cyclins $\mathrm{A}$ and $\mathrm{D}$, and are susceptible factors in $\mathrm{HCC}$ responsive to ER stress (49). Future studies on these cell cycle cyclins and their relationship to ER stress related proteins should help to understand better the cell death mechanisms of DHA.

Because oxidant/antioxidant balance, an important factor for initiation and progression of cancer and lipid peroxidation, has been cited as an important component of DHA toxicity (11), we therefore measured the antioxidant enzymes. Both SOD and glutathione are antioxidants capable of scavenging free radicals or reactive oxidative species (ROS). Some reports have suggested that the accumulation of oxygen radicals in malignancies is actually accompanied by a reduction in SOD activity $(50,51)$. In mouse myeloma cells, $\omega-3$ fatty acids enhanced formation of superoxide anion, hydrogen peroxide and lipid peroxides but also caused reduced levels of antioxidant enzymes such as SOD, glutathione peroxidase (52). The increased protein level of SOD2 in the DHA-treated cells was unclear to us, and only SOD1 gene has been shown to play an important role in determining the sensitivity of different tumor cells to the cytotoxic effects of DHA $(52,53)$. Elevated level of glutathione has been found in a number of tumor cell lines including liver cancer, which confer resistance against drugs or radiation therapies $(54,55)$. The unchanged protein level of glutathione synthetase observed in this cell line may imply that this enzyme plays a lesser role in DHA-mediated-free radicals toxicity in the MHCC97L cell line, DHA has been shown to induce apoptosis via reduced glutathione extrusion and lipid peroxidation in the human $\mathrm{PaCa}-44$ pancreatic cell line. We suspect that other free radical scavenger enzymes such as catalase, glutathione peroxide, glutathione reductase as well as the SOD1 gene may be involved and should be considered in future studies.

In summary, the present study indicates that DHA can affect the cell cycle progression and induces cell death of the human hepatocarcinoma MHCC97L cell line. The S-phase duration delay via suppression of the cell cycle regulatory proteins cyclin A, cyclin E and their Cdk2 kinase partner may account in part for the reduced growth of the cancer cells. Our data indicate that multiple pathways, often overlapping, for the DHA effect on cell growth and viability exist. Further studies are awaited to explore the complex molecular mechanisms for DHA action on human liver cancer. For instance, heat shock proteins may play an essential role in the maintenance of several signaling molecules, most of which are oncogenic kinases. Whether the inhibition of heat shock proteins induces ER stress, which leads to disruption of mitochondrial homeostasis, resulting in apoptosis and is partially responsible for the cytotoxicty of DHA on human liver cancer cells, are all important areas awaiting to be explored.

\section{Acknowledgements}

This study was supported by grants of the Strategic Research Theme on Cancer by The University of Hong Kong.

\section{References}

1. German JB, Roberts MA and Watkins SM: Genomics and metabolomics as markers for the interaction of diet and health: lessons from lipids. J Nutr 133: S2078-S2083, 2003.

2. Heller AR, Rössel T, Gottschlich B, Tiebel O, Menschikowski M, Litz RJ, Zimmermann T and Koch T: Omega-3 fatty acids improve liver and pancreas function in postoperative cancer patients. Int J Cancer 111: 611-616, 2004.

3. Norrish AE, Skeaff CE, Arribas GL, Sharpe SJ and Jackson RT: Prostate cancer risk and consumption of fish oils: a dietary biomarker-based case-control study. Br J Cancer 81: 1238-1242, 1999.

4. Reddy BS: Chemoprevention of colon cancer by dietary fatty acids. Cancer Metastasis Rev 13: 285-302, 1994.

5. Rose DP, Connolly JM, Rayburn J and Coleman M: Influence of diets containing eicosapentaenoic or docosahexaenoic acid on growth and metastasis of breast cancer cells in nude mice. J Natl Cancer Inst 87: 587-592, 1995.

6. Smith LC, Dauchy EM, Dauchy RT, Sauer LA, Blask DE, Davidson LK, Krause JA and Lynch DT: Dietary fish oil deactivates a growth-promoting signaling pathway in hepatoma 7288CTC in Buffalo rats. Nutr Cancer 56: 204-213, 2006.

7. Calviello G, Palozza P, Piccioni E, Maggiano N, Frattucci A, Franceschell P and Bartoli GM: Dietary supplementation with eicosapentaenoic and docosahexaenoic acid inhibits growth of Morris hepatocarcinoma 3924A in rats: effects on proliferation and apoptosis. Int J Cancer 75: 699-705, 1998.

8. Coleman WB: Mechanisms of human hepatocarcinogenesis. Curr Mol Med 3: 573-588, 2003.

9. Seitz HK and Stickel F: Risk factors and mechanisms of hepatocarcinogenesis with special emphasis on alcohol and oxidative stress. Biol Chem 387: 349-360, 2006.

10. Bosch FX, Ribes J and Borràs J: Epidemiology of primary liver cancer. Semin Liver Dis 19: 271-285, 1999.

11. Lee M and Bae MA: Docosahexaenoic acid induces apoptosis in CYP2E1-containing HepG2 cells by activating the c-Jun Nterminal protein kinase related mitochondrial damage. J Nutr Biochem 18: 348-354, 2007.

12. Simopoulos AP, Kifer RR and Martin RE: Health effects of polyunsaturated fatty acids in seafoods. Academic Press Inc., New York, pp319-531, 1986.

13. Stubbs CD and Smith AD: The modification of mammalian membrane polyunsaturated fatty acid composition in relation to membrane fluidity and function. Biochim Biophys Acta 779: 89-137, 1984.

14. Bandyopadhyay GK, Hwang S, Imagawa W and Nandi S: Role of polyunsaturated fatty acids as signal transducers: amplification of signals from growth factor receptors by fatty acids in mammary epithelial cells. Prostaglandins Leukot Essent Fatty Acids 48: 71-78, 1993.

15. Istfan NW, Wan JM, Bistrian BR and Chen ZY: DNA replication time accounts for tumor growth variation induced by dietary fat in a breast carcinoma model. Cancer Lett 86: 177-186, 1994.

16. Albino AP, Juan G, Traganos F, Reinhart L, Connolly J, Rose DP and Darzynkiewicz Z: Cell cycle arrest and apoptosis of melanoma cells by docosahexaenoic acid: association with decreased $\mathrm{pRb}$ phosphorylation. Cancer Res 60: 4139-4145, 2000.

17. Chen ZY and Istfan NW: Docosahexaenoic acid, a major constituent of fish oil diets, prevents activation of cyclin-dependent kinases and S-phase entry by serum stimulation in HT-29 cells. Prostaglandins Leukot Essent. Fatty Acids 64: 67-73, 2001.

18. Terano T, Tanaka T, Tamura Y, Kitagawa M, Higashi H, Saito Y and Hirai A: Eicosapentaenoic acid and docosahexaenoic acid inhibit vascular smooth muscle cell proliferation by inhibiting phosphorylation of Cdk2-cyclinE complex. Biochem Biophys Res Commun 254: 502-506, 1999.

19. Lundberg AS and Weinberg RA: Control of the cell cycle and apoptosis. Eur J Cancer 35: 531-539, 1999.

20. Rao CV and Reddy BS: Modulating effect of amount and types of dietary fat on ornithine decarboxylase, tyrosine protein kinase and prostaglandins production during colon carcinogenesis in male F344 rats. Carcinogenesis 14: 1327-1333, 1993. 
21. Tian J, Tang ZY, Ye SL, Liu YK, Lin ZY, Chen J and Xue Q: New human hepatocellular carcinoma (HCC) cell line with highly metastatic potential (MHCC97) and its expressions of the factors associated with metastasis. Br J Cancer 81: 814-821, 1999.

22. Li Y, Tang Z, Ye S, Liu B, Liu Y, Chen J and Xue Q: Establishment of a hepatocellular carcinoma cell line with unique metastatic characteristics through in vivo selection and screening for metastasis-related genes through cDNA microarray. J Cancer Res Clin Oncol 129: 43-51, 2003.

23. Mosmann T: Rapid colorimetric assay for cellular growth and survival: application to proliferation and cytotoxicity assays. J Immunol Methods 65: 55-63, 1983.

24. Wan JMF, Sit WH and Louie JCY: Polysaccharopeptide enhances the anticancer activity of doxorubicin and etoposide on human breast cancer cells ZR-75-30. Int J Oncol 32: 689-699, 2008.

25. Dolbeare F, Gratzner H, Pallavicini MG and Gray JW: Flow cytometric measurement of total DNA content and incorporated bromodeoxyuridine. Proc Natl Acad Sci USA 80: 5573-5577, 1983.

26. Begg AC, McNally NJ, Shrieve DC and Kärcher H: A method to measure the duration of DNA synthesis and the potential doubling time from a single sample. Cytometry 6: 620-626, 1985.

27. White RA, Terry NH and Meistrich ML: New methods for calculating kinetic properties of cells in vitro using pulse labelling with bromodeoxyuridine. Cell Tissue Kinet 23: 561573,1990

28. Fogt F, Wan JM, O'Hara C, Bistrain BR, Blackburn GL and Istfan NW: Flow cytometric measurement of cell kinetics in rat walker-256 carcinoma following in vivo and in vitro pulse labelling with bromodeoxyuridine. Cytometry 12: 33-41, 1991

29. Sherr CJ: G1 phase progression: cycling on cue. Cell 79: 551-555, 1994.

30. Hu KQ: Cyclooxygenase 2 (COX2)-prostanoid pathway and liver diseases. Prostaglandins Leukot Essent Fatty Acids 69: 329-337, 2003.

31. Wu T: Cyclooxygenase-2 in hepatocellular carcinoma. Cancer Treat Rev 32: 28-44, 2006.

32. Jurkowski JJ and Cave WTJ: Dietary effects of menhaden oil on the growth and membrane lipid composition of rat mammary tumors. J Natl Cancer Inst 74: 1145-1150, 1985.

33. Tang TCM, Poon RTP and Fan ST: The significance of cyclooxygenase- 2 expression in human hepatocellular carcinoma, Biomed Pharmacother 59: S311-S316, 2005.

34. Strillacci A, Griffoni C, Sansone P, Paterini P, Piazzi G, Lazzarini G, Spisni E, Pantaleo MA, Biasco G and Tomasi V: MiR-101 downregulation is involved in cyclooxygenase-2 overexpression in human colon cancer cells. Exp Cell Res 315 1439-1447, 2009.

35. Wan JM, Istfan NW, Chu CC, Blackburn GL and Bistrian BR Comparative effects of omega- 3 and omega- 6 polyunsaturated fatty acids on protein metabolism in rats bearing the mammary adenocarcinoma. Metabolism 40: 577-584, 1991.

36. Siddiqui RA, Jenski LJ, Harvey KA, Wiesehan JD, Stillwell W and Zaloga GP: Cell-cycle arrest in Jurkat leukaemic cells: a possible role for docosahexaenoic acid. Biochem J 371: 621-629, 2003.

37. Tang ZY, Ye SL, Liu YK, et al: A decade's studies on metastasis of hepatocellular carcinoma. J Cancer Res Clin Oncol 130 187-196, 2004

38. Cheng AS, Chan HL, Leung WK, Wong N, Johnson PJ and Sung JJ: Specific COX-2 inhibitor, NS-398, suppresses cellular proliferation and induces apoptosis in human hepatocellular carcinoma cells. Int J Oncol 23: 113-119, 2003.

39. Nagahara T, Okano J and Murawaki Y: Mechanisms of antiproliferative effect of JTE-522, a selective cyclooxygenase-2 inhibitor, on human liver cancer cells. Oncol Rep 18: 1281-1290, 2007.
40. Marui N, Sakai T, Hosokawa N, et al: N-myc suppression and cell cycle arrest at G1 phase by prostaglandins. FEBS Lett 270: 15-18, 1990.

41. Akiba J, Ogasawara S, Kawahara A, et al: N-myc downstream regulated gene 1 (NDRG1)/Cap43 enhances portal vein invasion and intrahepatic metastasis in human hepatocellular carcinoma. Oncol Rep 20: 1329-1335, 2008.

42. Chua MS, Sun H, Cheung ST, Mason V, Higgins J, Ross DT, Fan ST and So S: Overexpression of NDRG1 is an indicator of poor prognosis in hepatocellular carcinoma. Mod Pathol 20: 76-83, 2007.

43. Ciocca DR, Fanelli MA, Cuello-Carrion F and Calderwoodet SK: Implications of heat shock proteins in carcinogenesis and cancer progression. In: Heat Shock Proteins in Cancer. Springer, Dordrecht, pp31-52, 2007.

44. Yasuda E, Kumada T, Takai S, Ishisaki A, Noda T, MatsushimaNishiwaki R, Yoshimi N, Kato K, Toyoda H, Kaneoka Y, Yamaguchi A and Kozawa O: Attenuated phosphorylation of heat shock protein 27 correlates with tumor progression in patients with hepatocellular carcinoma. Biochem Biophys Res Commun 337: 337-342, 2005

45. Lim SO, Park SG, Yoo JH, Park YM, Kim HJ, Jang KT, Cho JW, Yoo BC, Jung GH and Park CK: Expression of heat shock proteins (HSP27, HSP60, HSP70, HSP90, GRP78, GRP94) in hepatitis B virus-related hepatocellular carcinomas and dysplastic nodules. World J Gastroenterol 11: 2072-2079, 2005.

46. King KL, Li AF, Chau GY, Chi CW, Wu CW, Huang CL and Lui WY: Prognostic significance of heat shock protein-27 expression in hepatocellular carcinoma and its relation to histologic grading and survival. Cancer 88: 2464-2470, 2000.

47. Baumeister P, Dong D, Fu Y and Lee AS: Transcriptional induction of GRP78/BiP by histone deacetylase inhibitors and resistance to histone deacetylase inhibitor-induced apoptosis. Mol Cancer Ther 8: 1086-1094, 2009.

48. Daneshmand S, Quek ML, Lin E, et al: Pinski, glucoseregulated protein GRP78 is up-regulated in prostate cancer and correlates with recurrence and survival. Hum Pathol 38: 1547$1552,2007$.

49. Chiang PC, Hsu JL, Yeh TC, Pan SL and Guh JH: Elucidation of susceptible factors to endoplasmic reticulum stress-mediated anticancer activity in human hepatocellular carcinoma. Naunyn Schmiedebergs Arch Pharmacol 377: 167-177, 2008.

50. Satomi A, Murakami S, Hashimoto T, Ishida K, Matsuki M and Sonoda M: Significance of superoxide dismutase (SOD) in human colorectal cancer tissue: correlation with malignant intensity. J Gastroenterol 30: 177-182, 1995.

51. Jeon SH, Park JH and Chang SG: Expression of antioxidant enzymes, catalase, superoxide dismutase, and glutathione peroxidase, in human bladder cancer. Korean J Urol 48: 921-926, 2007.

52. Kumar GS and Das UN: Free radical-dependent suppression of growth of mouse myeloma cells by alpha-linolenic and eicosapentaenoic acids in vitro. Cancer Lett 92: 27-38, 1995.

53. Ding WQ, Vaught JL, Yamauchi $\mathrm{H}$ and Lind SE: Differential sensitivity of cancer cells to docosahexaenoic acid-induced cytotoxicity: the potential importance of down-regulation of superoxide dismutase 1 expression. Mol Cancer Ther 3: 1109-1117, 2004.

54. Huang ZZ, Chen C, Zeng Z, et al: Mechanism and significance of increased glutathione level in human hepatocellular carcinoma and liver regeneration. FASEB J 15: 19-21, 2001.

55. Balendiran GK, Dabur R and Fraser D: The role of glutathione in cancer. Cell Biochem Funct 22: 343-352, 2004 